\title{
BLICKDIAGNOSE
}

Drei Brustwarzen - Polythelie

\section{Warum Sie hier die Nieren prüfen müssen}

\section{Bei der körperlichen Untersuchung eines 36-jährigen männlichen Patienten zeigte sich nebenbefundlich unterhalb der linken Mamille eine weitere, etwas kleinere Mamille.}

- Bei dem Vorliegen einer akzessorischen Mamille stellten wir die Diagnose einer Polythelie.

Akzessorische Mamillen sind phylogenetisch Hemmungsrückbildungen, die in der sogenannten Milchleiste lokalisiert sind. Die Milchleiste stellt eine im zweiten Embryonalmonat entstehende Epidermisleiste dar, die von der Axilla nach inguinal zieht. Akzessorische Mamillen sollen bei beiden Geschlechtern in 1-2\% der Bevölkerung mit einer familiären Häufung zu finden sein. Meist liegen sie uni- oder bilateral unterhalb den Brustdrüsen und sind mit Milchdrüsengewebe assoziiert. Differenzialdiagnostisch müssen akzessorische Mamillen von pigmentierten dermalen Nävuszellnävi unterschieden werden.

Da die Polythelie als ein potenzielles Symptom verschiedener Dysplasien der Niere und der ableitenden Harnwege beschrieben wurde, sollte bei den betroffenen $\mathrm{Pa}$ tienten regelmäßig eine sonografische Kontrolle erfolgen. Therapeutisch kann bei chronischer mechanischer Irritation oder aus kosmetischen Gründen eine Exzision dieses ansonsten benignen Befundes durchgeführt werden.

\section{Keyword: polythelia}

- PD Dr. med, Andreas Körber, Prof. Dr. med. Joachim Dissemond, Universitätsklinikum Essen, Klinik und Poliklinik für Dermatologie, Venerologie und Allergologie, Hufelandstraße 55, D-45122 Essen

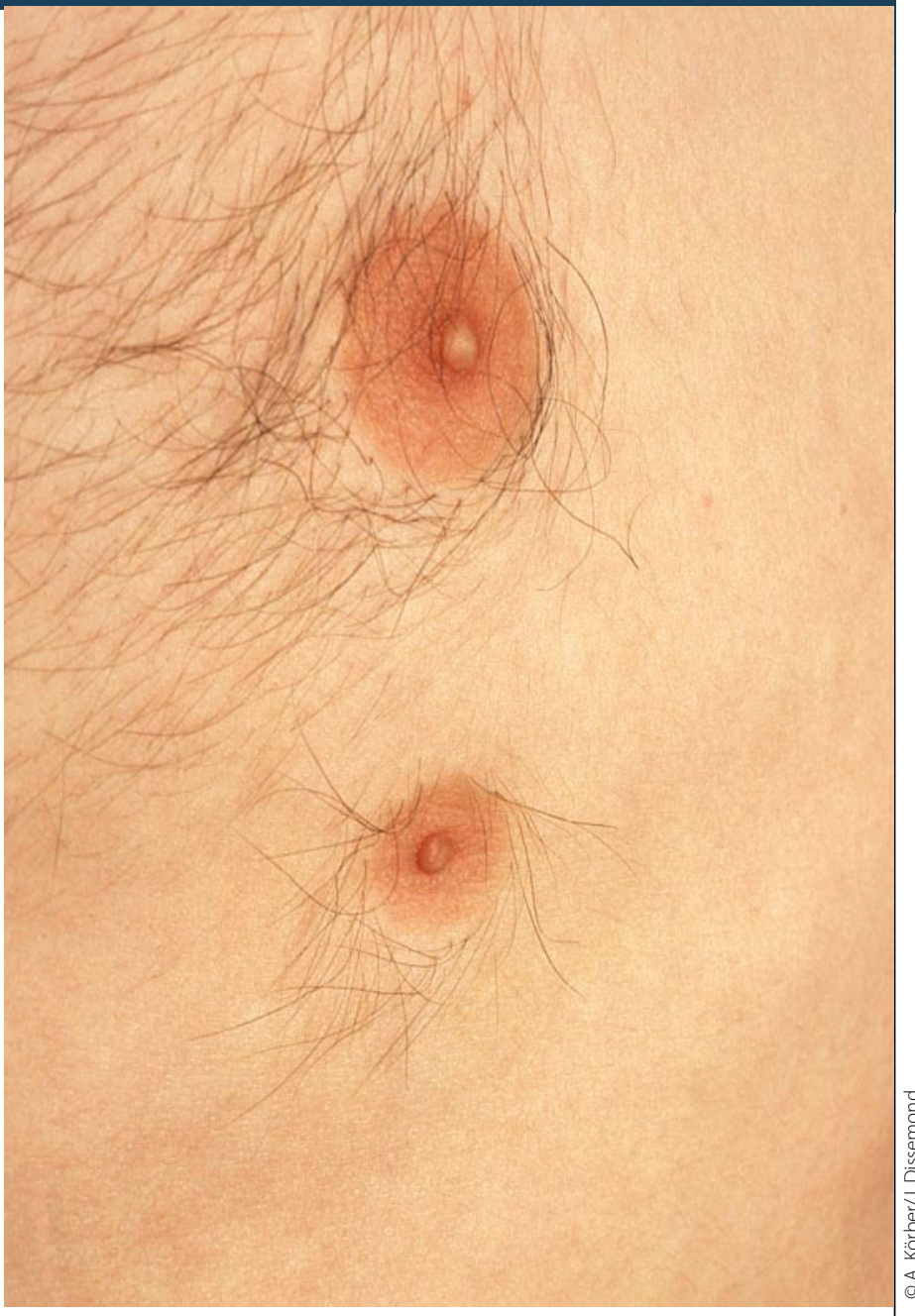

Ihr besonderer Fall?

\section{Stellen Sie uns Ihren Fall vor}

Sicher sehen auch Sie ab und an einen besonders eindrucksvollen Befund in Ihrer Praxis. Fotografieren Sie ihn, schreiben Sie uns unter dem Stichwort Blickdiagnose, bei Veröffentlichung erhalten Sie 100 Euro.

MMW-Fortschritte der Medizin

E-Mail: reinhold.manhart@springer.com

Fax: 089/203043-31424

\section{www.springermedizin.de}

Weitere Blickdiagnosen finden Sie im Internet unter:

http://www.springermedizin.de/blickdiagnose 